\title{
FORMATION OF TEMPERATURE CRACKS OF CONCRETE IN HIGH-RISE BUILDINGS AND THE CORRESPONDING MEASURES
}

\begin{abstract}
L. GUO ${ }^{1}$
A lot of heat will generate in mass concrete after pouring to form temperature cracks, which will reduce structural stiffness. This paper briefly introduces the principle of solid heat conduction and the cause of temperature crack formation and then used COMSOL software to simulate and analyze the mass concrete. The results showed that the simulation model had enough reliability to analyze the temperature change; the internal and external temperature of concrete rose first and then decreased; the formation of temperature crack was related to the internal and external temperature difference; the internal and external temperature difference was inversely proportional to the heat conductivity coefficient of concrete and directly proportional to the pouring temperature. Then, according to the analysis results, two measures were put forward to prevent temperature cracks in mass concrete: selecting concrete materials with high thermal conductivity, i.e., selecting coarse aggregate and fine aggregate with larger heat conductivity coefficient and reducing concrete pouring temperature, i.e., selecting cement with lower hydration heat, paying attention to temperature reduction in the process of concrete stirring, and reducing the amount of cement.
\end{abstract}

Keywords: mass concrete, temperature crack, temperature stress, preventive measures

\section{INTRODUCTION}

With the rapid development of China' s economy, the influx of a large number of people into the economically developed first-and second-tier cities has accelerated the local infrastructure construction, and the number and scale of high-rise buildings have been increasing [1]. Generally

\footnotetext{
${ }^{1} \mathrm{PhD}$., School of Civil Engineering, Luoyang Institute of Science and Technology, Luoyang, Henan 471023, China, email: glliguo@yeah.net
} 
speaking, the minimum section size of mass concrete is not less than $80 \mathrm{~cm}$ [2]. At first, mass concrete was used as building materials in water conservancy projects, but later, with the maturity of related technologies, it was gradually applied to high-rise buildings. Mass concrete is usually cast on site in high-rise buildings. Moreover, different from ordinary concrete, there will be no reinforcement in mass concrete, making its application relatively simple. However, when the mass concrete is poured, the cement and other gel materials will generate a large amount of hydration heat during the solidification process. The poor heat dissipation will make the central temperature of concrete rise rapidly, resulting in the formation of internal and external temperature differences. Under the constraint of foundation, the thermal stress will result in temperature cracks, which will not only affect the appearance, but also reduce the stiffness of the structure [3]. Therefore, measures need to be taken to prevent it. Huang [4] regarded the prevention of pier concrete cracks as a multifactor system optimization problem and studied the optimization method of pier concrete temperature control measures using uniform design method and neural network model. He found that pier concrete should adopt inner tube cooling and adopt reasonable surface insulation measures and low concrete pouring temperature. Schackow et al. [5] studied the effect of pouring temperature and material composition on thermal conductivity of concrete and found that the thermal conductivity of concrete could be improved by using cement with small hydration heat and reducing the thickness of concrete. Shen [6] et al. studied the crack resistance of high performance concrete (HPC) at curing temperature by thermoplastic test and put forward the autogenous shrinkage model of HPC considering curing temperature. The experimental results showed that the HPC specimens cured at constant temperature of $20{ }^{\circ} \mathrm{C}$ had better crack resistance than those cured at constant temperature of $45{ }^{\circ} \mathrm{C}$ and cured adiabatically. In this paper, the principle of solid heat conduction and the causes of temperature cracks were briefly introduced. Then the concrete was simulated and analyzed by COMSOL software, and the corresponding preventive measures were put forward.

\section{PRinciple of heat CONDUCTION}

The process and influencing factors of concrete cracks caused by temperature was discussed; hence heat transfer that causes temperature change is bound to be involved in exploring the formation principle. The heat change of mass concrete in high-rise buildings belongs to solid heat conduction, and the relationship between the heat change in solid and its temperature change [7] is: 


$$
q=\frac{Q}{t \bullet S} \propto-\nabla T
$$

where $q$ is the heat flow that represents the change of heat, $Q$ stands for the heat that is conducted in the solid, ${ }^{t}$ represents the time of heat conduction, $S$ represents the effective area through which heat passes, $\nabla T$ stands for the change gradient of solid temperature, and the negative sign stands for the opposite direction. According to the principle of energy conservation, equation (1) is extended to:

$$
\left\{\begin{array}{l}
q=-\lambda \nabla T \\
\frac{\partial}{\partial x} c \rho T=-\nabla T
\end{array},\right.
$$

where $\lambda$ stands for the thermal conductivity coefficient of solid, $x$ represents the distance of heat conduction, ${ }^{c}$ stands for the specific heat of solid, and $\rho$ is the density of solid. The negative sign in equation (2) still represents the opposite direction.

Next, for the convenience of calculation, the shape of mass concrete was supposed as cuboid, and the length, width and height were $x, y, z$ respectively. According to equation (2) and the principle of heat balance [8],

$$
a \frac{\partial T}{\partial t} d t d x d y d z=\left[\lambda\left(\frac{\partial^{2} T}{\partial x^{2}}+\frac{\partial^{2} T}{\partial y^{2}}+\frac{\partial^{2} T}{\partial z^{2}}\right)+Q_{i n}\right] d t d x d y d z
$$

The left side of the equation is the heat needed to raise the temperature of concrete, and the right side is the sum of the effective heat provided by the environment and the internal heat generated by physical or chemical reasons in concrete. $Q_{\text {in }}$ is the heat generated inside concrete.

By simplifying equation (3), the heat conduction equation of concrete is obtained:

$$
\frac{\partial T}{\partial t}=\frac{\lambda}{c \rho}\left(\frac{\partial^{2} T}{\partial x^{2}}+\frac{\partial^{2} T}{\partial y^{2}}+\frac{\partial^{2} T}{\partial z^{2}}\right)+\frac{Q_{i n}}{c \rho}
$$

It can be seen from the concrete heat conduction equation (4) that the temperature change of a specified concrete is related to time and internal heat production, that is to say, for equation (4) 
which is used for describing the temperature variation of a specified concrete, it has two unknowns numbers, $t$ and $Q_{i n}$. There are innumerable solutions satisfying equation (4) from the mathematical point of view, but the special value solution is needed in practical application; hence it is necessary to add initial and boundary conditions [9] to equation (4).

The time to start calculation of temperature change of concrete is set as 0 , then the initial condition is the temperature distribution condition of concrete when $t=0$, and the boundary condition is the law of temperature variation when heat exchanges between concrete surface and outside, which can be divided into three categories, as shown in Table 1.

Table 1. Three boundary conditions

\begin{tabular}{|c|c|c|}
\hline Number & $\begin{array}{c}\text { Expressions of relevant } \\
\text { formulas }\end{array}$ & Remarks \\
\hline $\begin{array}{c}\text { The first kind of boundary } \\
\text { condition }\end{array}$ & $(2.5) \quad T=f(t)$ & $\begin{array}{c}\text { The surface temperature of } \\
\text { concrete is only related to time, } \\
\text { and it is in contact with known } \\
\text { water at that moment. }\end{array}$ \\
\hline $\begin{array}{c}\text { The second kind of boundary } \\
\text { condition }\end{array}$ & $(2.6) \quad q=h \Delta t$ & $\begin{array}{c}\text { At that time, the surface heat } \\
\text { flux of concrete is known. } \Delta t \text { is } \\
\text { heat flux passing time. }\end{array}$ \\
\hline $\begin{array}{c}\text { The third kind of boundary } \\
\text { condition }\end{array}$ & $(2.7) \quad-\lambda\left(\frac{\partial t}{\partial n}\right)_{w}=h \Delta t$ & $\begin{array}{c}\text { At that time, only another solid } \\
\text { contacts with the concrete } \\
\text { surface, and moreover the } \\
\text { temperature and heat flux } \\
\text { change of the contact surface } \\
\text { change is continuous. }\end{array}$ \\
\hline
\end{tabular}

\section{CAUSES OF TEMPERATURE CRACKS}

In high-rise buildings, a large number of mass concrete is usually used, such as load-bearing walls. Mass concrete has large size, with dense steel bar distribution and large cement consumption. It is more prone to cracks than small concrete during and after construction. The causes and types of internal stress in concrete are various, but the main stress comes from the temperature stress in the temperature field.

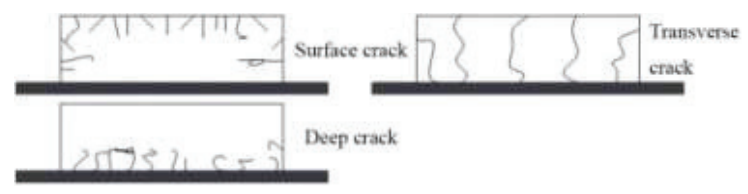

Fig. 1. Schematic diagram of concrete cracks 
As shown in Fig. 1, the surface crack [10] is caused by the opposite stress torque inside and outside the concrete because of the slow heat dissipation inside and fast heat dissipation outside at the initial stage after the pouring of concrete. Deep crack is formed by the extension of surface crack. After the cement solidification, the internal temperature gradually decreases and cools, and moreover, due to the connection between the concrete and foundation, it is pulled by restraint stress. In the process of cooling shrinkage, the surface cracks generated before will have concentration of stress and develop into deep cracks. Transverse crack forms when the concrete further shrinks as the residual water inside evaporates after cooling and it is pulled by restraint stress because of the connection between the concrete and foundation.

The temperature crack of mass concrete can be divided into three stages according to the change process of temperature stress: the rising stage and cooling stage which generates the early stress and the stable stage which generates late stress. It is assumed that concrete is in adiabatic environment, then the temperature inside concrete is composed of pouring temperature and temperature generated by hydration heat. The formula for calculating pouring temperature [11] is:

$$
\left\{\begin{array}{l}
T_{o}=\frac{\left(c_{1} T_{1} m_{1}+c_{2} T_{2} m_{2}+c_{3} T_{3} m_{3}+c_{4} T_{4} m_{4}+c_{4} T_{1} m_{5}+c_{4} T_{2} m_{6}\right)}{m_{1}+m_{2}+m_{3}+m_{4}+m_{5}+m_{6}} \\
T_{a}=T_{o}+\left(T_{b}-T_{o}\right)\left(\alpha_{1}+\alpha_{2}+, \Lambda,+\alpha_{n}\right)
\end{array},\right.
$$

where $T_{o}, T_{a}, T_{b}$ are the mixing temperature, pouring temperature and ambient temperature of concrete, $c_{i}$ is the corresponding specific heat capacity, $i=1,2,3,4$ corresponding to cement, sand, stone and water, $T_{i}$ is the corresponding to temperature, $i=1,2,3,4$ corresponding to cement, sand, stone and water, $m_{i}$ stands for the corresponding quality, $i=1,2,3$ corresponding to anhydrous cement, sand and stone and $i=4,5,6$ corresponding to free water in cement, sand and stone, and $\alpha$ represents the coefficient of temperature loss.

The formula for calculating the temperature change of hydration heat [12] is:

$$
\left\{\begin{array}{l}
T(t)=\frac{C Q(1-\exp (-m t))}{c \rho} \\
T_{\max }=T_{o}+\delta T(t) \\
\delta=\frac{T_{m}}{T_{n}}
\end{array},\right.
$$


where $T(t)$ stands for temperature rise of concrete under adiabatic condition in t-age period, $C$ stands for cement content, $Q$ stands for heat release from hydration of unit cement, $m$ stands for the empirical coefficient adjusted according to the type of cement and temperature, $t$ is the age of cement pouring, $T_{\max }$ stands for the highest temperature, $\delta$ is the cooling coefficient, $T_{n}$ is the theoretical temperature rise under adiabatic condition, and $T_{m}$ is the actual temperature rise caused by hydration heat.

By using the finite element method, the mass concrete will be discretized into several node elements, and then the nodal force and bearing load are integrated to obtain an equilibrium equation [13]:

$$
K \Delta \theta_{n}=\Delta P_{n}^{L}+\Delta P_{n}^{T}+\Delta P_{n}^{O}+\Delta P_{n}^{S}
$$

where $K$ is the overall stiffness matrix of concrete, $\Delta \theta_{n}$ is the displacement increment of $\mathrm{n}$ nodes, $\Delta P_{n}$ is the load increment of different nodes, and $L, T, O, S$ represent the causes of load variation caused by external load, temperature, spontaneous deformation and dry shrinkage of concrete respectively. Equation (3.3) is solved, and the stress increment of the node is calculated. The temperature stress field of concrete can be obtained by accumulating the stress increment.

\section{SimULATION ANALYSIS}

\subsection{EXPERIMENTAL ENVIRONMENT}

In this study, COMSOL software [14] was used to simulate the model based on the mass concrete in the engineering example. The experiment was carried out on a laboratory server. The server configuration was Windows 7 system, I7 processor and 16G memory. 


\subsection{RELEVANT PARAMETER SETTING}

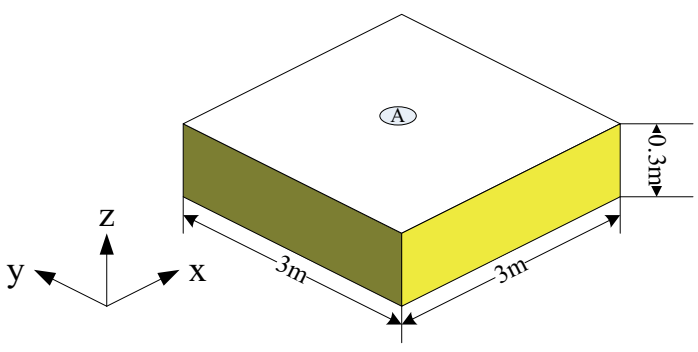

Fig. 2. Schematic diagram of concrete model

As shown in Fig. 2, the cuboid concrete in an engineering example was selected as the simulation model for convenience of calculation. The size of the model was $30 m \times 30 m \times 3 m$. Point $\mathrm{A}$ is the measuring point, and the temperature was measured on the surface of A point and at the center of the model corresponding to Point A. The thermal conductivity coefficient of concrete used in engineering example was $1.9 \mathrm{~W} /(\mathrm{m} \cdot \mathrm{K})$, the specific heat capacity was $890 \mathrm{~J} /(\mathrm{kg} \cdot \mathrm{K})$, and the density is $2500 \mathrm{~kg} / \mathrm{m}^{3}$.

\subsection{EXPERIMENT ITEM}

(1) The initial temperature of concrete was set as $20{ }^{\circ} \mathrm{C}$, the boundary conditions of left and right sides were set as adiabatic, and the way of fixing around and bottom was hot lotus root, and the thermal conductivity was as described above. The ambient temperature of the simulation model was set as the change range of the actual ambient temperature, $20 \sim 23{ }^{\circ} \mathrm{C}$.

(2) The thermal conductivity coefficient of concrete in the simulation model was set as a variable, $1.8 \sim 10.5 \mathrm{~W} /(\mathrm{m} \cdot \mathrm{K})$. The ambient temperature was constant at $20^{\circ} \mathrm{C}$, and the other parameters of the simulation models were the same as those of item (1).

(3) The initial temperature of concrete in the simulation model was set as a variable, $20 \sim 35^{\circ} \mathrm{C}$, and the ambient temperature was constant at $20^{\circ} \mathrm{C}$. The other simulation parameters were the same as those in item (1). 


\subsection{DETERMINATION CRITERIA}

According to the relevant specifications for mass concrete [15], the internal temperature of concrete should not exceed $25{ }^{\circ} \mathrm{C}$. The possibility and size of cracks will be large when the temperature exceeds $25^{\circ} \mathrm{C}$.

\subsection{EXPERIMENTAL RESULTS}

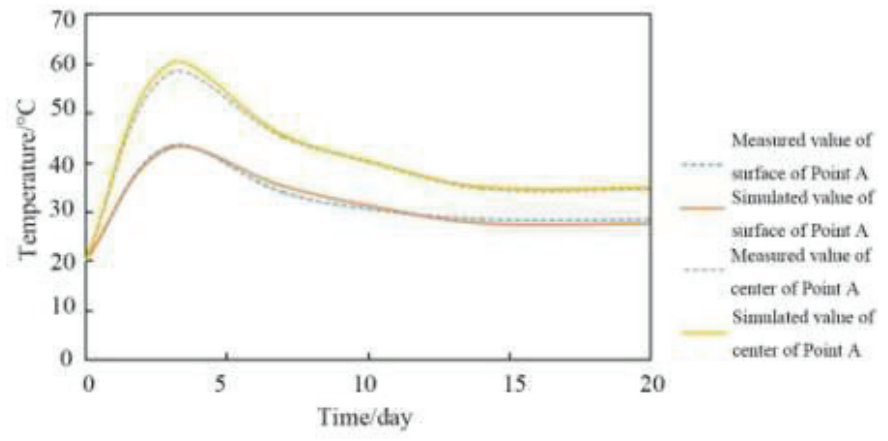

Fig. 3. Variation curves of measured and simulated values at Point A of concrete

Table 2. Errors between simulated and measured values

\begin{tabular}{|c|c|c|c|c|c|c|}
\hline Age & $\begin{array}{c}\text { Surface } \\
\text { measured } \\
\text { value at } \\
\text { Point } \mathrm{A} /{ }^{\circ} \mathrm{C}\end{array}$ & $\begin{array}{c}\text { Surface } \\
\text { Simulated } \\
\text { value at } \\
\text { Point A/ } /{ }^{\circ} \mathrm{C}\end{array}$ & $\begin{array}{c}\text { Relative } \\
\text { error } / \%\end{array}$ & $\begin{array}{c}\text { Measured } \\
\text { value at the } \\
\text { center of } \\
\text { Point A } /{ }^{\circ} \mathrm{C}\end{array}$ & $\begin{array}{c}\text { Simulation } \\
\text { value at the } \\
\text { center of } \\
\text { Point A } /{ }^{\circ} \mathrm{C}\end{array}$ & $\begin{array}{c}\text { Relative } \\
\text { error/\% }\end{array}$ \\
\hline 3 & 43.2 & 42.8 & -0.93 & 58.0 & 59.9 & 3.28 \\
\hline 7 & 33.8 & 35.1 & 3.85 & 45.0 & 45.5 & 1.11 \\
\hline 10 & 30.5 & 31.2 & 2.30 & 40.0 & 40.2 & 0.50 \\
\hline 14 & 28.4 & 27.6 & -2.82 & 34.6 & 35 & 1.16 \\
\hline 20 & 28.3 & 27.5 & -2.83 & 34.4 & 34.8 & 1.16 \\
\hline
\end{tabular}

As shown in Fig. 3, with the increase of concrete age, the overall temperature (surface temperature + central temperature) increased first and then decreased, while the central temperature of concrete was always higher than the surface temperature. It can be seen from Fig. 3 that when the concrete age reached the third day, its temperature reached the maximum value, and at that moment the measured temperature difference between the surface and the center of Point A was $14.8{ }^{\circ} \mathrm{C}$, and the simulated temperature difference was $17.1^{\circ} \mathrm{C}$. The two kinds of temperature differences did not 
exceed $25{ }^{\circ} \mathrm{C}$ required by the mass concrete specification, thus the concrete will not produce temperature cracks. Combining with Fig. 3 and Table 2, it can be seen that the temperature simulation curve of the simulation model basically coincided with the actual curve and the relative error between the numerical values was smaller than 5\%. It suggested that the model had high reference value in engineering analysis.

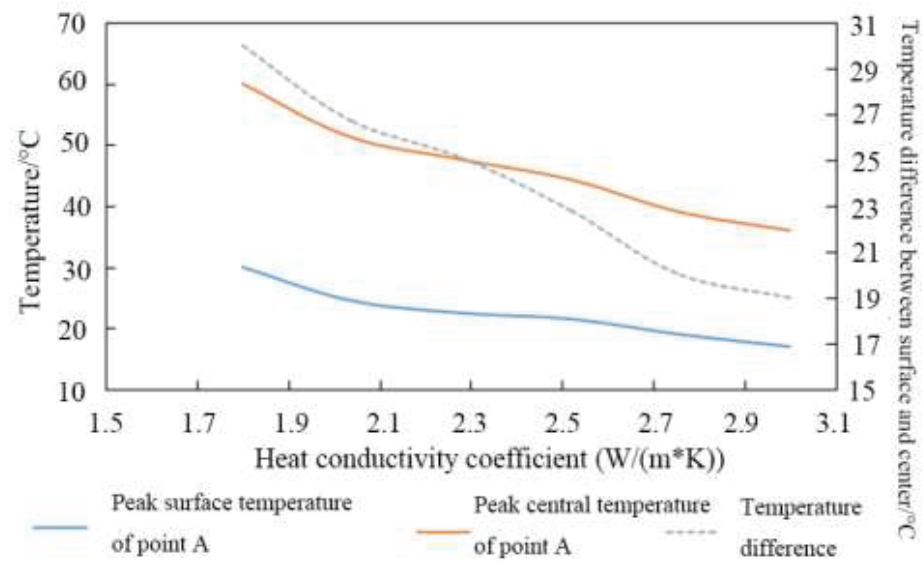

Fig. 4. Temperature variation of surface and center of Point A under different thermal conductivity coefficients

As shown in Fig. 4, with the increase of the thermal conductivity coefficient of the concrete simulation model, the surface temperature and central temperature of the concrete model decreased, while the central temperature decreased more significantly; the temperature difference between the surface and center decreased with the increase of the thermal conductivity coefficient. When the thermal conductivity coefficient was smaller than $5.4 \mathrm{~W} /(\mathrm{m} \cdot \mathrm{K})$, the temperature difference between the surface and center of the concrete was greater than $25^{\circ} \mathrm{C}$, and the temperature stress inside the concrete was too large, which was easy to form temperature cracks. When the thermal conductivity coefficient exceeded $25^{\circ} \mathrm{C}$, the temperature difference between the surface and center was smaller than $25^{\circ} \mathrm{C}$ and the internal temperature stress decreased, which was not easy to form temperature cracks. 


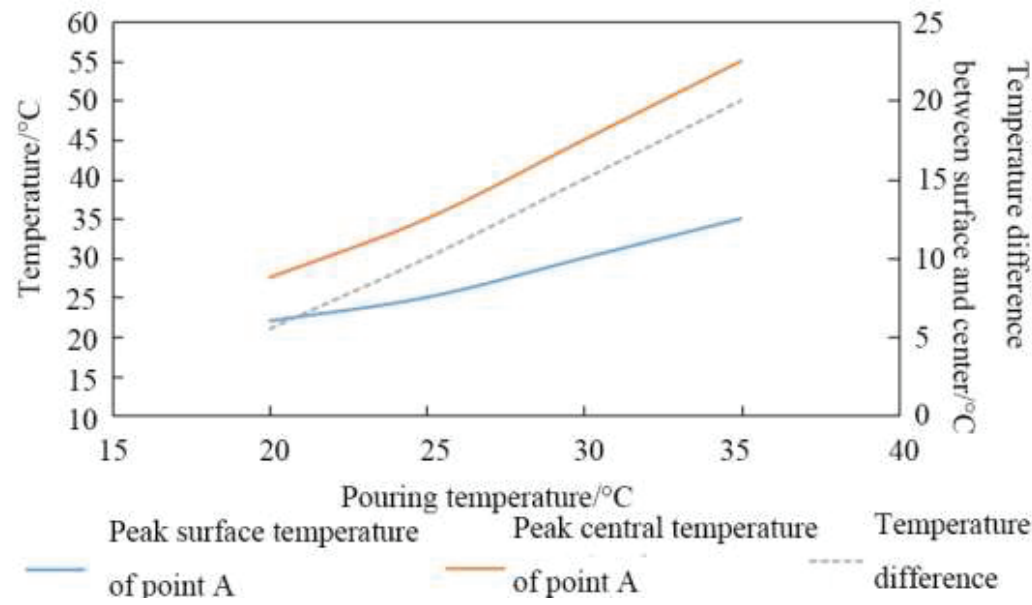

Fig. 5. Temperature variation of the surface and center of Point A of the concrete at different pouring temperatures

As shown in Fig. 5, with the increase of concrete pouring temperature, the surface and central temperatures of the concrete increased linearly, and the central temperatures increased rapidly. Moreover, the temperature difference between them increased linearly, but it did not exceed $25{ }^{\circ} \mathrm{C}$ required by mass concrete specification, which was impossible to cause temperature cracks.

\subsection{DISCUSSION AND PROPOSAL OF CORRESPONDING MEASURES}

According to the agreement between the measured and simulated temperature values of Point $\mathrm{A}$ of the concrete in item (1), the simulation model had a considerable degree of reliability, and on the whole, most of the simulated values were larger than the measured values. The reason was that in the actual project, the environment is not as ideal as that of the simulation model and thermal convection also exits on the surface of concrete besides heat conduction.

The results of item (2) showed that the higher the thermal conductivity coefficient of concrete, the easier the heat generated inside the concrete will be transmitted to the outside world, and the smaller the temperature difference between inside and outside, the smaller the temperature stress formed. Therefore, the preventive measures are to choose the cement and sand with high thermal conductivity coefficient, so as to achieve higher thermal conductivity coefficient of concrete and reduce the internal and external temperature difference and temperature stress. 
The result of item (3) reflected that the increase of concrete pouring temperature meant the increase of initial temperature inside concrete. With the accumulation of internal hydration heat, the central temperature was higher. Moreover, the surface of concrete contacted with the environment directly, and the temperature decreased quickly and approached the ambient temperature, so the temperature difference between inside and outside and the temperature stress increased. It can be seen that another preventive measure is to reduce the pouring temperature of concrete and not to pour concrete in extremely cold or hot environment.

\section{CONCLUSION}

In this paper, the principle of solid heat conduction and the causes of temperature cracks were briefly introduced. Then the simulation analysis was carried out by COMSOL software. The simulation model could be used to analyze the temperature change of concrete, and the temperature change inside and outside of the concrete increased first and then decreased. The increase of thermal conductivity coefficient could decrease the temperature difference between inside and outside of the concrete, which reduced the generation risk of temperature cracks. Increasing pouring temperature can increase the temperature difference between inside and outside of the concrete, which was easy to form temperature cracks. Two measures were put forward to prevent temperature cracks, selecting concrete materials with high thermal conductivity coefficient and reducing the pouring temperature of concrete or choosing suitable environmental temperature for pouring. 


\section{REFERENCES}

1. Z. C. Mao, D. Wang, Y. B. Liu, "Measures to control the Temperature of the Concrete Cracks in Foundation Mass", Applied Mechanics and Materials 723: 4, 2015.

2. M. Batog, Z. Giergiczny, "Impact of mass concrete constituents on its properties", Construction \& Building Materials 146: 221-230, 2017.

3. J. Ren, S. Lu, "Characterizing air void effect on fracture of asphalt concrete at low-temperature using discrete element method", Engineering Fracture Mechanics 170: S0013794416306646, 2016.

4. Y. Huang, "Optimization of temperature-control measures for concrete structures: a case study of the sluice project", Advances in Civil Engineering 2018: 1-8, 2018.

5. A. Schackow, C. Effting, I. R. Gomes, et al., "Temperature variation in concrete samples due to cement hydration”, Applied Thermal Engineering 103: 1362-1369, 2016.

6. D. J. Shen, J. L. Jiang, J. X. Shen, P. P. Yao, G. Q. Jiang, "Impact of curing temperature on autogenous shrinkage and cracking resistance of high-performance concrete at an early age", Construction and Building Materials 103: 67-76, 2016.

7. W. R. L. D. Silva, V. Šmilauer, P. Štemberk, "Upscaling semi-adiabatic measures for simulating temperature evolution of mass concrete structures", Materials \& Structures 48(4): 1031-1041, 2015.

8. X. Yu, J. Chen, X. Qiang, et al., "Research on the influence factors of thermal cracking in mass concrete by model experiments", KSCE Journal of Civil Engineering (2): 1-10, 2017.

9. C. Qian, G. Gao, Z. H. He, et al., "Feasibility research of using phase change materials to reduce the inner temperature rise of mass concrete", Journal of Wuhan University of Technology (Science Edition) 30(5): 989994, 2015.

10. W. Zhou, C. Feng, X. Liu, et al., "Contrastive digital investigations on thermo-structural behaviors in mass concrete with various cements", Materials 9(5): 378, 2016.

11. T. A. Yikici, H. L. Chen, "Use of maturity method to estimate compressive strength of mass concrete", Construction \& Building Materials 95: 802-812, 2015.

12. Z. Wang, T. Li, L. Yi, et al., "Temperature control measures and temperature stress of mass concrete during construction period in high-altitude regions", Advances in Civil Engineering 2018: 1-12, 2018.

13. Z. C. Mao, D. Wang, Y. B. Liu, "Measures to control the temperature of the concrete cracks in foundation mass", Applied Mechanics \& Materials 723: 309-312, 2015.

14. F. Zunino, J. Castro, M. Lopez, "Thermo-mechanical assessment of concrete microcracking damage due to early-age temperature rise", Construction \& Building Materials 81(6): 140-153, 2015.

15. Z. Si, Q. Zhang, L. Z. Huang, et al., "Development of simulation program for temperature field of mass concrete structures", E3S Web of Conferences 38, 2018.

\section{LIST OF FIGURES AND TABLES:}

Fig. 1. Schematic diagram of concrete cracks

Fig. 2. Schematic diagram of concrete model

Fig. 3. Variation curves of measured and simulated values at Point A of concrete

Fig. 4. Temperature variation of surface and center of Point A under different thermal conductivity coefficients

Fig. 5. Temperature variation of the surface and center of Point A of the concrete at different pouring temperatures

Tab. 1. Three boundary conditions

Tab. 2. Errors between simulated and measured values 